\title{
Atypical presentation of syphilis as an aphthous ulcer
}

\author{
Diane J. Lu MD PhD, Ariella Zbar MD MPH
}

- Cite as: CMAJ 2017 May 29;189:E748. doi: 10.1503/cmaj.161197

A 28-year-old nulliparous woman presented to an ambulatory outpatient clinic with a one-month history of a nonhealing aphthous ulcer on her inner lower lip that initially caused mild discomfort when eating. Saline rinses and a corticosteroid oral gel were ineffective. She had unprotected oral and vaginal sex on one occasion with a male partner one month before symptom onset. She did not have any genitourinary or constitutional symptoms, and did not smoke. She had not been immunized with recombinant human papillomavirus quadrivalent vaccine. Upon clinical examination, she had a nontender, firm, well-circumscribed, skin-coloured round macule with a rolled border on the mucosal membrane of the lower lip, without evidence of lymphadenopathy (Figure 1). The differential diagnosis included syphilitic chancre, oral herpes simplex virus and malignant disease. A swab of the lesion was negative for herpes simplex virus.

A prior screening test for syphilis had been nonreactive; however, serology testing for syphilis was now reactive for treponema

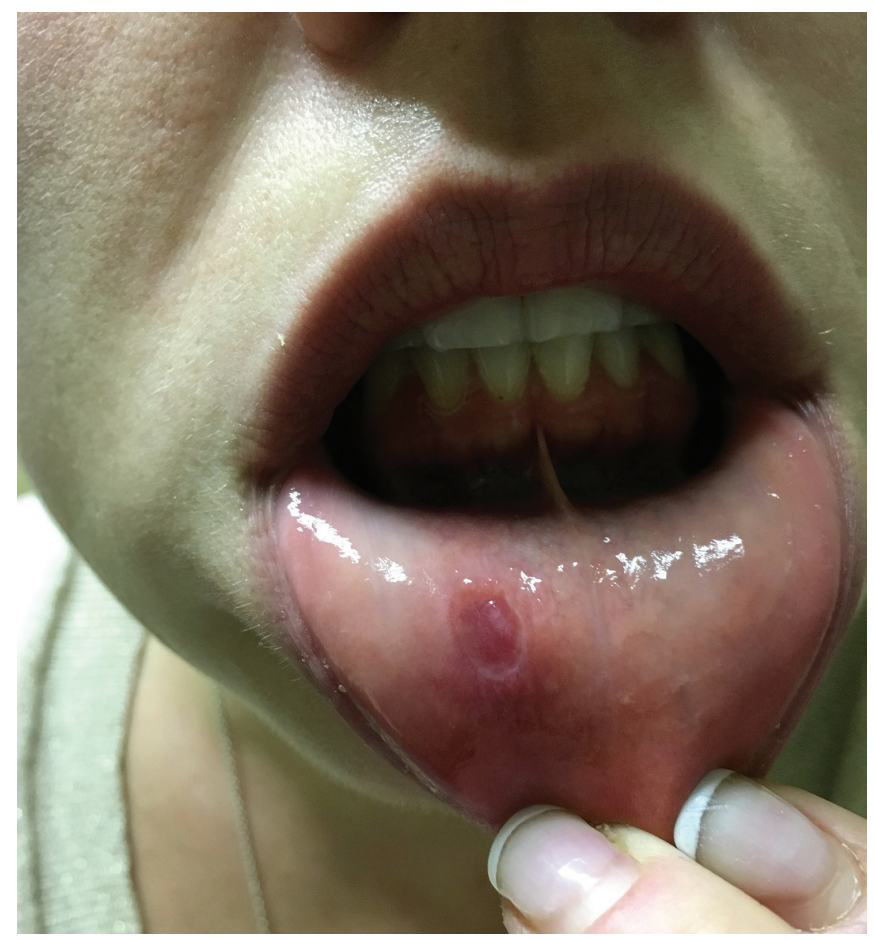

Figure 1: Chancre, characteristic of primary syphilis, on the lower lip of a 28-year-old woman. pallidum antibody, with a result of $1: 8$ for a rapid plasma reagin test, confirming primary syphilis given the oral chancre. ${ }^{1,2}$ The patient was prescribed treatment with benzathine penicillin (2.4 million international units in a single dose intramuscularly). After treatment ended, a repeat rapid plasma reagin test was nonreactive, with a reactive serology test for treponema pallidum antibody, which is consistent with previously treated syphilis infection.

Although infectious syphilis is the least common of Canada's three nationally reportable bacterial sexually transmitted infections, its incidence is increasing, with localized outbreaks in some Canadian cities. ${ }^{1}$ Infectious primary syphilis is spread sexually (oral, vaginal, anal) and has an incubation period of 10-90 days. ${ }^{3}$ Typically, a syphilitic oral chancre is a painless ulcer $(1-2 \mathrm{~cm}$ in size) with a firm, rolled edge. ${ }^{1-3}$ Diagnosis is made by nontreponemal and treponemal serological tests. ${ }^{1-3}$ Use of darkfield microscopy is not recommended for diagnosis of oral chancres, because of nonpathogenic treponemes may be found in samples of oral tissue. ${ }^{1}$

Management of primary syphilis includes first-line treatment with benzathine penicillin, testing for sexually transmitted infections and sexual abstinence pending resolution of symptoms after treatment. ${ }^{1-3}$ Repeat serological testing posttreatment is recommended ${ }^{1-3}$ in addition to contact tracing, and testing and treatment of sexual partners. ${ }^{1,2}$

\section{References}

1. Wong $\mathrm{T}$, Latham-Carmanico $\mathrm{C}$, editors. Canadian guidelines on sexually transmitted infections. Ottawa: Public Health Agency of Canada; 2010. Available: www.phac-aspc .gc.ca/std-mts/sti-its/cgsti-ldcits/section-5-10-eng.php (accessed 2016 May 9).

2. Workowski KA, Bolan GA. Sexually transmitted diseases treatment guidelines. Atlanta: Centers for Disease Control and Prevention; 2015. Available: www.cdc. gov/std/tg2015/syphilis.htm (accessed 2016 May 9).

3. Appendix A: disease-specific chapters. Chapter: Syphilis. In: Infectious disease protocol. Toronto: Ontario Ministry of Health and Long-Term Care; 2014. Available: www.health.gov.on.ca/en/pro/programs/publichealth/oph_standards/ docs/syphilis_chapter.pdf (accessed 2016 May 9).

\section{Competing interests: None declared.}

This article has been peer reviewed.

The authors have obtained patient consent.

Affiliations: Millhaven Institution (Lu), Bath, Ont.; Sudbury and District Health Unit (Zbar), Sudbury, Ont.

Correspondence to: Diane J. Lu, 82dl@queensu.ca 